\title{
Characterization of GPS total electron content (GPS-TEC) in Antarctica from 2004 to 2011
}

\author{
Emília Correia ${ }^{1,2, \star}$, Amanda Junqueira Paz ${ }^{2}$, Mauricio A. Gende ${ }^{3}$ \\ ${ }^{1}$ Instituto Nacional de Pesquisas Espaciais (INPE), São José dos Campos, Brazil \\ ${ }^{2}$ Centro de Rádio Astronomia e Astrofisica Mackenzie (CRAAM), Universidade Presbiteriana Mackenzie, São Paulo, Brazil \\ ${ }^{3}$ Universidad de La Plata, La Plata, Argentina
}

Article history

Received October 15, 2012; accepted March 27, 2013.

Subject classification:

Ionosphere, Total electron content, Seasonal variation, Solar cycle.

\begin{abstract}
The vertical total electron content (VTEC) obtained from 2004 to 2011 at Comandante Ferraz Brazilian Antarctic Station $\left(62.1^{\circ} \mathrm{S}, 58.4^{\circ} \mathrm{W}\right)$ is analyzed to study the mean diurnal, seasonal and annual variations. The maximum daytime VTEC had an annual variation that decreased from 2004 to 2008, and then starting to increase in 2009, which followed the variation of the solar activity. The daily VTEC shows good linear correlation with solar radiation intensity, which is also dependent on the solar zenithal angle. The mean diurnal VTEC shows a semiannual variation, with larger peaks in equinoxes for all years; no winter anomaly was observed, and in summer, there was no clear diurnal variation. The semiannual variation of the VTEC is also modulated by solar activity, with larger VTEC peaks when the solar activity was higher.
\end{abstract}

\section{Introduction}

The total electron content (TEC) has been used to study the ionosphere behavior for different sectors, with particular interest in an understanding of its mean diurnal, seasonal and annual variations, as well as its dependence on solar activity level. Most vertical (V)TEC variation studies have been carried out at equatorial and low latitudes [e.g., Huang and Cheng 1995, and references therein, Mansilla et al. 2005, Galav et al. 2010, Natali and Meza 2011, Liu et al. 2012, Kumar et al. 2012, Olwedo et al. 2012]. At high latitudes, and particularly in Antarctica, global positioning system (GPS)-TEC studies had been carried out mostly during geomagnetic storm events [Coker et al. 1995, Aarons et al. 2000, Krankowski et al. 2005], and only a few have looked at seasonal variation [Kitamura et al. 2009, Chung et al. 2011, Purohit et al. 2011].

Long-term VTEC studies have shown that the ionosphere is not only controlled by the solar zenith angle, and that temporal and spatial anomalies have been frequently observed. The main anomalies are: the winter or seasonal anomaly, such that the TEC daytime values at mid-latitudes are larger in winter than in summer; and the semiannual anomaly, such that the TEC is greater at equinox than at solstice. From a study of the global distribution of the amplitude of various anomalies, Zhao et al. [2007] showed that these are modulated by the solar activity, and that the daytime TEC seasonal anomaly is most evident at middle to high latitudes in the northern hemisphere, while the semiannual anomaly is seen at all latitudes, with it being more pronounced in the equatorial anomaly crest region $\left( \pm 20^{\circ}\right.$ magnetic latitudes). The winter anomaly has been more clearly observed during periods when the Sun has been highly active [Walker 1971, Huang and Cheng 1995, Mansilla et al. 2005].

The aim of the present study was to investigate the ionosphere variations using GPS-TEC measurements obtained at Comandante Ferraz Brazilian Antarctic Station (EACF; $62.1^{\circ} \mathrm{S}, 58.4^{\circ} \mathrm{W}$ ) at King George Island on the Antarctic Peninsula. We present the results for yearly, seasonal and mean diurnal VTEC variations as observed at EACF under different solar activity levels in the period from 2004 to 2011, and thus during the decay phase of the $23^{\text {rd }}$ solar cycle, and the increase of the $24^{\text {th }}$ solar cycle.

\section{Observations}

The data used for this study were obtained with a dual frequency Javad GPS receiver that has been operating at EACF since January 2004. The GPS-TEC was obtained from Receiver Independent Exchange Format (RINEX) data that were acquired every $15 \mathrm{~s}$. The analysis uses the VTEC derived from GPS-TEC observations using the pre-processing stage of the local point interpolation method (LPIM) algorithm, which uses a simple mapping function. The LPIM algorithm was developed 


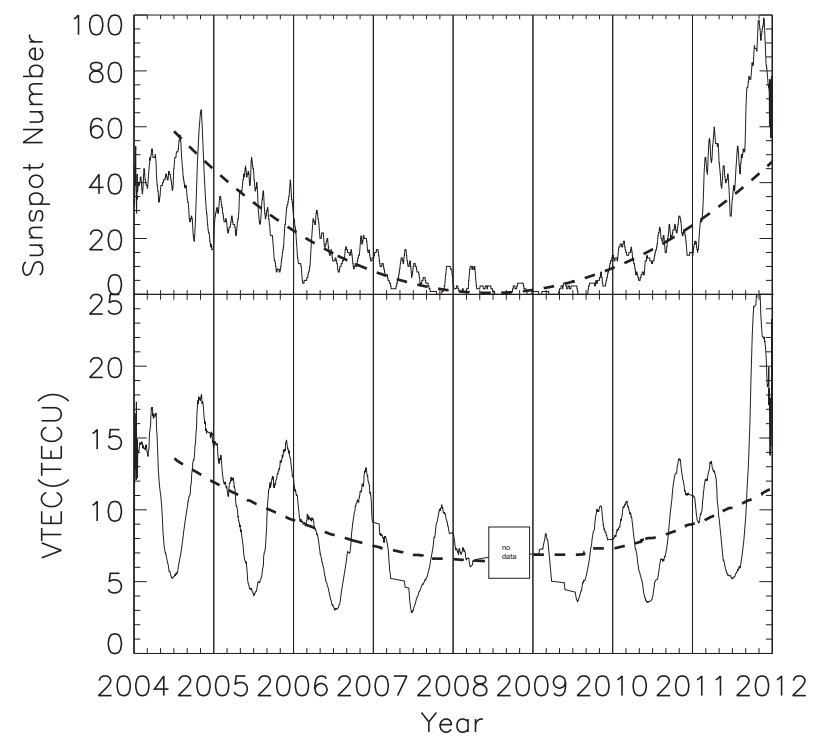

Figure 1. Variation of sunspot numbers (a) and the daily maximum VTEC (b) from 2004 to 2011. Both datasets were 31-day smoothed and fitted using a cubic polynomial regression (dashed curves).

by the Argentine La Plata Group [Brunini et al. 2008]. The VTEC was computed as the median VTEC values of the satellites available above a $30^{\circ}$ elevation angle, at each $30 \mathrm{~s}$, with the ionosphere height assumed at 350 $\mathrm{km}$. The analysis covers the period from 2004 to 2011, but there are some data gaps due instrumental problems, especially during the spring months of 2008.

The influence of solar activity on the long-term VTEC variation was evaluated considering the solar ultraviolet radiation $\left(\mathrm{F}_{\mathrm{UV}}\right)$ and sunspot number as solar proxies (data obtained from the National Oce-

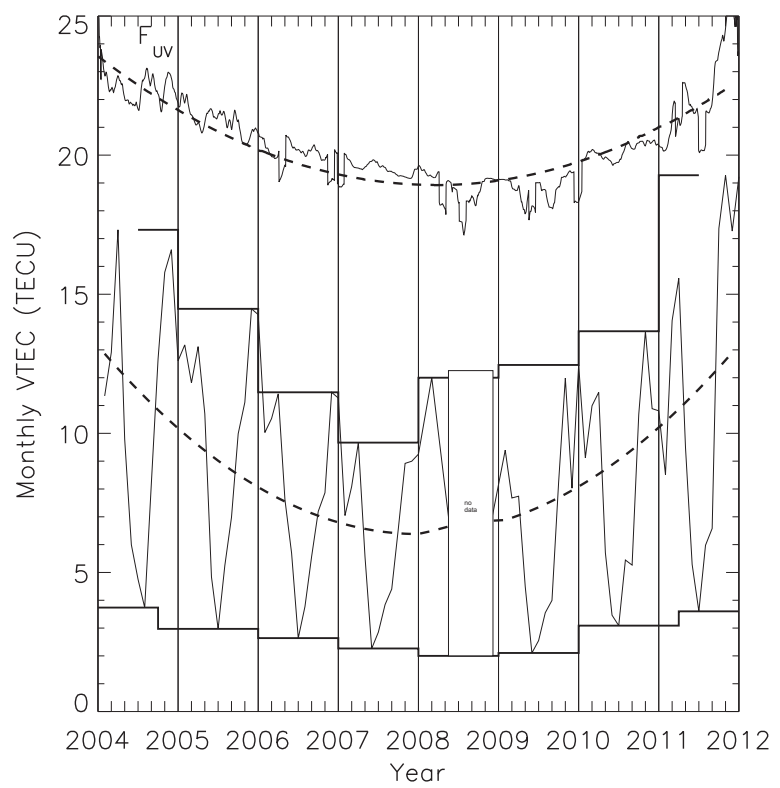

Figure 2. Variation of the 31-day smoothed solar He II radiation $\left(30.4 \mathrm{~nm}, \mathrm{~F}_{\mathrm{UV}}\right)$ (top) and the monthly averaged daily maximum VTEC (lower curve) from 2004 to 2011. The yearly maximum and minimum VTEC values are also shown. Both datasets were fitted using cubic polynomial regression (dashed curves). anic and Atmospheric Administration data center at http:/ / www.swpc.noaa.gov/ftpdir/indices/; last accessed September, 2012). The $\mathrm{F}_{\mathrm{UV}}$ data refer to the TIMED SEE (Thermosphere Ionosphere Mesosphere Energetics and Dynamics - Solar Extreme Ultraviolet [EUV] Experiment) and SORCE SOLSTICE (Solar Radiation and Climate Experiment - Soar-Stellar Irradiance Comparison Experiment) solar spectral irradiance measurements of the He II $30.4 \mathrm{~nm}$ emission provided by the Laboratory for Atmospheric and Space Physics (LASP) Solar Irradiance Data Center (http: / / lasp.colo rado.edu/lisird/lya/; last accessed September, 2012) [Woods et al. 2000].

\section{Observational results and discussion}

\subsection{Long-term variation - solar radiation control}

To study the solar influence in the long-term variation of the VTEC, we considered the daily median value obtained between 15:00 UT and 17:00 UT $(\sim 12: 00$ LT) as representative of the maximum daily VTEC, from 2004 to 2011. The comparisons were carried out considering the 31-day running mean of the daily maximum VTEC with the sunspot number (Figure 1), and the monthly average of the daily maximum VTEC with solar FUV intensity (Figure 2). The analyses show good temporal correlation between VTEC and solar activity, where all of the datasets have a slow variation that was well fitted by a third-degree polynomial (Figure 1, dashed lines). The wrapping of the monthly VTEC data in Figure 2 is the yearly maximum and minimum values. The results clearly show daytime VTEC modulation by the solar activity, which decreased from 2004 to 2008 during the decay of the $23^{\text {rd }}$ solar cycle, and starting to increase in 2009 when the $24^{\text {th }}$ solar cycle began.

To evaluate the influence of the solar activity on the maximum daytime VTEC, we compared the 3-day smoothed VTEC data with the daily $\mathrm{F}_{\mathrm{UV}}$ solar intensity (Figure 3). This comparison was carried out considering the months of January and July separately, which are representative of the summer and winter seasons, respectively, in order to filter the solar zenith angle effect. The analysis shows a strong linear correlation between the VTEC and the solar $\mathrm{F}_{\mathrm{UV}}$ intensity in summer, as demonstrated by the correlation coefficient (R) of $0.84\left(R^{2}=0.71\right)$; this means that $71 \%$ of the data are well represented by a linear variation with a gradient of $1.70 \mathrm{TECU} /\left(10^{-3} \mathrm{~W} / \mathrm{m}^{2} / \mathrm{nm}\right)$. However, in winter, the correlation coefficient is weak, at $0.56\left(\mathrm{R}^{2}=0.31\right)$, which means that only $31 \%$ of the data can be explained by the linear relationship with a gradient of $0.44 \mathrm{TECU} /$ $\left(10^{-3} \mathrm{~W} / \mathrm{m}^{2} / \mathrm{nm}\right)$. These results mean that the maximum daytime VTEC is modulated by the solar radia- 
tion intensity but depends on the solar zenith angle, as shown by the higher gradient in the summer season.

The long-term analysis of the daytime VTEC measured at EACF from 2004 to 2011 clearly shows that it is modulated by solar activity. This is in agreement with Chung et al. [2011], who used VTEC measurements carried out from 2005 to 2009 over King Sejong station $\left(\sim 62^{\circ} \mathrm{S}, 58^{\circ} \mathrm{W}\right)$, which is very near the Brazilian station. Modulation of the VTEC by solar activity was also reported by Walker [1971], Huang and Cheng [1995], Zhao et al. [2007] and Galav et al. [2010]. These results also showed that the VTEC correlation with the solar radiation intensity at a latitude of $\sim 62^{\circ} \mathrm{S}$ is different between the summer and winter seasons, demonstrating that the ionization processes are lower in winter (Figure 3), probably due to low solar flux at high solar zenith angles, as shown by Purohit et al. [2011] from observations carried out in the polar region.

\subsection{Seasonal mean diurnal variation}

The seasonal mean diurnal variation was obtained by considering the monthly averages of the 1 -h VTEC for each day for January, March, June and September, as representative of the summer solstice, autumn equinox, winter solstice and spring equinox, respectively. The mean diurnal variation of the VTEC for each season for all of the years is shown in Figure 4, where there is a clear peak between 13:00 UT and 17:00 UT (LT = UT -4 ), but January (summer). The mean diurnal VTEC in the Antarctic summer shows no clear variation, which suggested higher values in the nighttime than in the daytime. This can be attributed to the Weddell Sea Anomaly, which refers to the larger nighttime electron density than for the daytime that has been observed around the Antarctica Peninsula [Horvarth 2006, Jee et al. 2009, Chung et al. 2011].

The diurnal VTEC shows a semiannual variation (Figure 4), with larger diurnal peaks occurring preferentially during the equinoxes, while the smallest peak occurs in the winter solstice for all of the years. The semiannual anomaly of the diurnal VTEC observed at EACF with maximum values at the equinoxes is similar to the observations from equatorial [Kumar et al. 2012, Olwedo et al. 2012], middle [Huang and Cheng 1995, Mansilla et al. 2005, Galav et al. 2010, Liu et al. 2012, Kumar et al. 2012] and high [Chung et al. 2011, Purohit et al. 2011] latitudes.

The diurnal peak of the VTEC for each season decreases from 2004 to 2008, to reach its lowest values in 2008-2009 when the solar activity was at a minimum, and then starts to increase after 2009, with the up-coming $24^{\text {th }}$ solar cycle.

In summary, the long-term study of the daily and

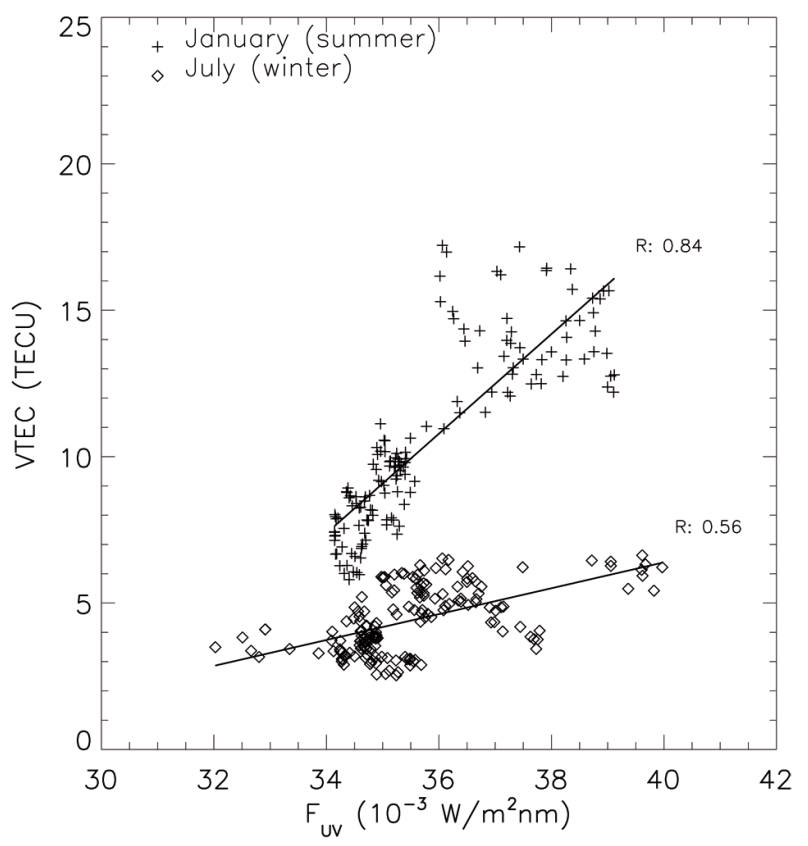

Figure 3. Variations of the 3-day smoothed daily maximum VTEC for January (summer) and July (winter) with respect to the solar $\mathrm{F}_{\mathrm{UV}}$ intensity used as a proxy for the solar activity. Both datasets were fitted with linear regression ( $\mathrm{R}$, correlation coefficients).

monthly maximum daytime VTEC at EACF show annual variation in close association with the solar cycle, which decreased from 2004 to 2008 during the decay of the $23^{\text {rd }}$ solar cycle, and which started to increase in 2009 when the $24^{\text {th }}$ solar cycle began. The solar control of the VTEC is also verified by its good linear correlation with the solar flux intensity, which has been shown to be dependent on the solar zenith angles, as demonstrated by the higher VTEC gradients in summer than in winter. The results also show the presence of a semiannual anomaly, with the daytime VTEC peaks occurring during equinoxes. A winter anomaly was not observed in this study.

\section{Concluding remarks}

The ionosphere behavior was investigated using the maximum daytime GPS-TEC observed at EACF from 2004 to 2011. We have discussed here the annual, seasonal and mean diurnal variations of the VTEC at a latitude of $\sim 62^{\circ} \mathrm{S}$ as a function of the solar activity.

The maximum daytime VTEC ( 12:00 LT) shows an annual variation that was clearly controlled by the solar activity and by the solar zenith angle, which was greater in summer than in winter, and was greater near the maximum solar activity than near the minimum. These data reinforce the idea that the ionosphere ionization processes are controlled by solar flux intensity and solar zenith angle, especially at higher latitudes [Purohit et al. 2011].

The VTEC shows a clear semi-annual anomaly with peaks during the equinoxes, similar to what has been ob- 

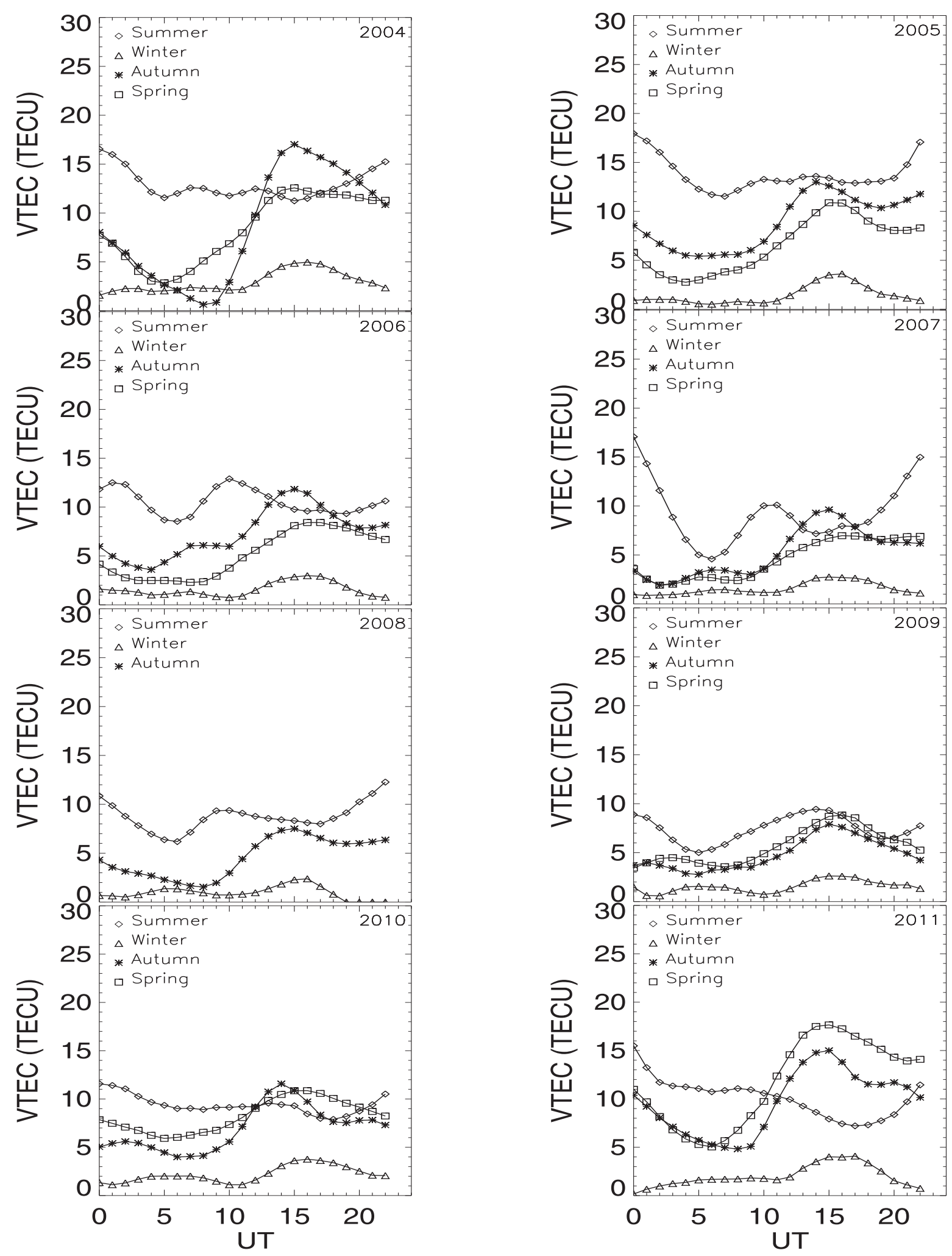

Figure 4. Seasonal variability of the VTEC for each year from 2004 to 2011. Each curve refers to the mean diurnal variation that is representative of each season, as observed at EACF $\left(\sim 62^{\circ} \mathrm{S}\right)$.

served at all latitudes; on the other hand, a winter (seasonal) anomaly was not observed, probably because it has the least chance to be observed in the South Pacific areas in the South America sector [Zhao et al. 2007].

Ionosphere studies covering the large spatial distribution of the VTEC are important to better characterize the longitudinal and latitudinal dependence on the anomalies. As the ionosphere can be controlled by an internal dynamic/ chemical process that is driven by solar radiation and an external process, such as magnetospheric disturbances or atmospheric waves from below, further studies are needed to investigate the major causes that are responsible for the anomalies in the ionosphere variations. 
Acknowledgements. This study was supported by CNPq/ PROANTAR (proc. 0520186/06-0 and 556872/2009-6) and partially by INCT-APA (Instituto Nacional de Ciência e Tecnologia Antártico de Pesquisas Ambientais, CNPq proc. 574018/2008-5 and FAPERJ proc. E-16/170.023/2008). EC thanks the CNPq (proc. 300710/2006-2) and the SECIRM, and the Brazilian Antarctic Program (PROANTAR) for logistic support at Comandante Ferraz Brazilian Antarctic Station. We also thank the referee for suggestions that helped to improve our manuscript.

\section{References}

Aarons J., B. Lin, M. Mendillo, K. Liou and M. Codrescu (2000). Global positioning system phase fluctuations and ultraviolet images from the Polar satellite, J. Geophys. Res., 105, 5201-5213.

Brunini, C., A. Meza, M. Gende and F. Azpilicueta (2008). South American regional ionospheric maps computed by GESA: a pilot service in the framework of SIRGAS, Adv. Space Res., 42, 737-744; doi:10.1016/j.asr.2007.08.041.

Chung, J.K., G. Jee and C.N. Lee (2011). Global positioning system total electron content variation over King Sejong Station in Antarctica under the solar minimum condition between 2005 and 2009, Journal of Astronomy and Space Sciences, 28 (4), 305310; doi:10.5140/JASS.2011.28.4.305.

Coker, C., R. Hunsucker and G. Lott (1995). Detection of auroral activity using GPS satellites, Geophys. Res. Lett., 22, 3259-3262.

Galav, P., N. Dashora, S. Sharma and R. Pandey (2010). Characterization of low latitude GPS-TEC during very low solar activity phase, J. Atmosph. Terrestr. Phys., 72, 1309-1317; doi:10.1016/j.jastp.2010.09.017.

Horvarth, I. (2006). A total electron content space weather study of the nighttime Weddell Sea Anomaly of 1996/1997 southern summer with TOPEX/ Poseidon radar altimetry, J. Geophys. Res., 111, A12317; doi:10.1029/2006JA011679.

Huang, Y.N., and K. Cheng (1995). Solar cycle variation of the total electron content around equatorial anomaly crest region in east Asia, J. Atmosph. Terrestr. Phys., 57, 1503-1511.

Jee, G., A.G. Burns, Y-H. Kim and W. Wang (2009). Seasonal and solar activity variations of the Weddell Sea Anomaly observed in the TOPEX total electron content measurements, J. Geophys. Res, 114, A04307; doi:10.1029/2008JA013801.

Kitamura, N., A. Shinbori, Y. Nishimura, T. Ono, M. Iizima and et al. (2009). Seasonal variations of the electron density distribution in the polar region during geomagnetically quiet periods near solar maximum, J. Geophys. Res., 114, A01206; doi:10.1029/2008JA 013288.

Krankowski, A., I.I. Shagimuratov, L.W. Baran and I.I. Ephishov (2005). Study of TEC fluctuations in
Antarctic ionosphere during storm using GPS observations, Acta Geophys. Polon., 53, 205-218.

Kumar, S., S. Priyadarshi, S.G. Krishna and A.K. Singh (2012). GPS-TEC variations during low solar activity period (2007-2009) at Indian low latitude stations, Astrophys. Space Sci., 339, 165-178; doi: 10.1007/s10 509-011-0973-6.

Liu, G., W. Huang, H. Shen and J. Gong (2012). Vertical TEC variations and model during low solar activity at a low latitude station, Xiamen, Adv. Space Res., 49, 530-538; doi:10.106/j.asr.2011.10.024.

Mansilla, G.A., M. Mosert and R.G. Ezquer (2005). Seasonal variation of the total electron content, maximum electron density and equivalent slab thickness at a South-American station, J. Atmosph. Terrestr. Phys., 67, 1687-1690; doi:10.1016/j.jastp.2005.02.024.

Natali, M.P., and A. Meza (2011). Annual and semiannual variations of vertical total electron content during high solar activity based on GPS observations, Annales Geophysicae, 29, 865-873; doi:10.5194/angeo29-865-2011.

Purohit, P.K., P. Bhawre, A.A. Mansoori, P.A. Khan and A.K. Gwal (2011). GPS derived total electron content (TEC) variations over Indian Antarctic Station, Maitri, World Acad. Sci. Engin. Technol., 59, 597-599.

Olwendo, O.J., P. Baki, C. Mito and P. Doherty (2012). Characterization of ionospheric GPS Total Electron Content (GPS-TEC) in low latitude zone over the Kenyan region during a very low solar activity phase, J. Atmosph. Terrestr. Phys., 84-85, 52-61; doi:10.1016/ j.jastp.2012.06.003.

Walker, G.O. (1971). Electron content and topside plasma temperature studies at low latitudes during a period from sunspot minimum to sunspot maximum, J. Atmosph. Terrestr. Phys., 33, 1041-1053.

Woods, T.N., W.K. Tobiska, G.J. Rottman and J.R. Worden (2000). Improved solar Lyman irradiance modeling from 1947 through 1999 based on UARS observations, J. Geophys. Res., 105, 27195-27215.

Zhao, B., W. Wan, L. Liu, T. Mao, Z. Ren, M. Wang and A.B. Christensen (2007). Features of annual and semiannual variations derived from the global ionospheric maps of total electron content, Annales Geophysicae, 25, 2513-2527; doi:10.5194/ angeo-252513-2007.

\footnotetext{
${ }^{\star}$ Corresponding author: Emília Correia, Centro de Rádio Astronomia e Astrofísica Mackenzie (CRAAM), Universidade Presbiteriana Mackenzie, São Paulo, Brazil; email: ecorreia@craam.mackenzie.br.
}

(C) 2013 by the Istituto Nazionale di Geofisica e Vulcanologia. All rights reserved. 